\title{
Habit Formation and Risk-free Rate Puzzle
}

\author{
Wonnho Choi ${ }^{1}$ \\ ${ }^{1}$ Institute of Finance and Banking, Seoul National Unversity, Republic of Korea \\ Correspondence: Wonnho Choi, Visiting Researcher, Institute of Finance and Banking, Seoul National Unversity, \\ Republic of Korea. E-mail: wonnho@lycos.co.kr \\ Received: May 21, 2014 \\ Accepted: September 16, 2014 \\ Online Published: October 13, 2014 \\ doi:10.5430/ijfr.v5n4p155 \\ URL: http://dx.doi.org/10.5430/ijfr.v5n4p155
}

\begin{abstract}
This paper deals with risk-free rate puzzle when the agent shows external habit formation, using different sorts of instruments that are used for proxies as a risk-free rate. It is found that upon instruments, risk free rate puzzle is vulnerable to the proxies selected; this fact ascribes to the partial solution to that puzzle. In addition, the external habit ratio model in contrast with time separable preferences exclusively contributes to the description of observed behavior of secular instruments. In particular, the degree of time-nonseparability of the former plays a remarkable role in solving out the discrepancy between observed and derived rate, lowering theoretical interest rate into the bottom of observed rate within reasonable risk aversion.
\end{abstract}

Keywords: risk-free rate puzzle, proxy for a relatively risk-free rate, time-separable preferences, external habit ratio model

\section{Introduction}

The risk free rate puzzle has for a long time puzzled both practitioners and scholars who have explored models capable of generating returns seen in real world. That matters since risk-free rate is the benchmark rate of a sure thing not merely for investors who consider a long-term investment along with hedging in light of time- and staterisk, but for short term investors. It is also related to the equity risk premium and used for derivative pricing by way of equivalent martingale measure in financial markets. Nonetheless, the theoretical models developed thus far cannot account for the observed returns of risk-free proxies. Theoretically, the expected rate of return from a utility-based model should be similar to realized returns. In reality, however, found is considerable evidence to the contrary. In other words, they do not match each other unless high-risk aversion coefficients are allowed (Kandel\&Stambaugh, 1991; Kocherlakota, 1996). This disconnect has long perplexed financial economists and cast doubt over the reasonable returns provided by professionals and practitioners to market participants. Further, it needs a solution to forecasting rational expected returns in an international capital market, aside from the U.S. stock market. To meet such a solution, a utility-based model has been used to offer a rational expected value for risk-free assets based on capitalistic egotism. However, this approach is not without its problems; for example, the interest rates derived from frequently used models show remarkable differences to the observations of the proxied interest rate. Weil (1989) terms this phenomenon the "risk-free rate puzzle."

This deviation from financial theory-based models affects the equity premium. Previous studies have shown that the size of the equity premium depends on that of its chosen counterpart in the financial market (Mehra\& Prescott, 2003; Siegel, 1992b). Hence, the risk-free rate puzzle seems to be chained to the equity premium puzzle. However, in attempting to solve the risk-free rate puzzle, the first notable predicament is the choice of a proxy for the risk-free rate. Even though it is conventional to use Treasury Bills (TBs) for this purpose, it is not parsimonious nor necessarily a fair investment comparison (Welch, 2000, p. 50). In empirical studies, several alternative instrumental tools have been used as a substitute for the risk-free rate in the U.S. capital market (Siegel, 1992a, 1992b, 1999, 2005; Cochrane, 1997; McGrattan\& Prescott, 2000; Jagannathan, McGrattan, E., \&Scherbina, 2000). In fact, the size of each puzzle varies across the measurement period in the U.S. stock market, depending on the chosen proxy. This indicates how crucial choosing a proper proxy as a counterpart to equity returns is, especially in long-term investments.

In order to solve the risk-free rate puzzle, this paper proposes two approaches. One approach is to use an alternative utility function. Previous studies have approached the risk-free rate and equity premium puzzles using either time additive preferences or Epstein and Zin's utility. Although the latter characterizes the state- and time-separability of preferences, it has not helped solve the risk-free rate puzzle thus far. Moreover, these two frequently used utilities 
have the drawback that they do not reflect the past consumption of the agent; hence, the covariability of asset returns along with consumption growth and the variability in consumption growth by itself seem to be low. (Note 1) A suggested model that serves our interest in consumption fluctuation is one based on habit formation. Such a model can accommodate the change in consumption level that has been influenced by realized asset returns with a few lagged periods of years. From a theoretical viewpoint, for example, Constantinides (1990) and Abel (1990, 1999) suggest solving the equity premium puzzle using a habit-based model. Meanwhile, Constantinides and Ferson (1991), and Ferson and Harvey (1992) prove empirically that a habit-based model is useful for the equity premium puzzle. This empirical evidence attributes habit persistence, based on seasonality, to habit formation. For these theoretical and documentary reasons, this paper focuses on habit-based models to account for the risk-free rate puzzle.

Another approach to the risk-free rate puzzle is by carrying out a sensitivity analysis of a proxy by checking the difference between implied and observed returns. As we show in this paper, the choice of a proxy for the risk-free rate as a counterpart to equity returns turns out to be vital to the risk free rate puzzle. Before the advent of TBs, diverse types of instruments were employed as a safe asset. Mehra and Prescott (2003) and Siegel (1992) present a variation in the equity premium with respect to which instruments are used to proxy for the return on a risk-free security. The latter paper emphasizes the variation in the proxy as a counterpart to equity, which is significantly higher before and after the period out of Mehra and Prescott (2003).In line with Siegel's (1992) study of a proxy for long- rather than short-term periods, other papers focus on longer-term bonds demanded by investors hedging intertemporal risks (see Siegel \&Thaler, 1997; Siegel, 1999; Jagannathan, McGrattan, \&Scherbina, 2000; Siegel, 2005). Notably, Siegel (2005) argues that a short-term risk-free rate may not be appropriate for long-term investors who should hedge against the shift in investment opportunities. All these papers suggest that the size of the equity premium is critically influenced by the chosen proxy for the risk-free rate or alternative counterpart and thus that the choice of a proxy may be crucial to both conundrums.

The remainder of this paper is organized as follows. Section 2 introduces the competing proxies for the risk-free rate. Section 2.1 introduces several studies on the equity premium and risk-free rate puzzles that estimate large differences in equity premiums among measures in the U.S. stock market. Correspondingly, section 2.2 describes the estimates and discrepancies of the equity premium in the Korean stock market with respect to which financial instrument has been chosen as a counterpart to equity returns. Section 3 addresses the models thus far used to analyze the risk-free rate puzzle. Section 3.1 illustrates the behavior of interest rates, consumption growth, and inflation from 1975 to 2008. Section 3.2 matches the first moment of the implied risk-free rate with the observed returns under the assumption of homoscedastic variance in consumption growth using time-separable preferences. Likewise, section 3.3 generates the implied risk-free rate using an external habit ratio model and compares the results with those from a time-separable utility. Section 4 concludes.

\section{Competing Proxies for the Risk-free Rate}

TBs are believed to be a historically representative proxy for the risk-free rate in the U.S. financial market, and they have thus been used to test the two puzzles explored in this study regardless of the presence of short- or long-term investors. In the Korean financial market, by contrast, several alternative proxies have been used for the risk-free rate to explain the risk premium and risk-free rate puzzles to estimate the parameters of a utility that would characterize a time preference and risk aversion coefficient. So far, however, there has been no consensus on which proxy is best among researchers investigating the two problems. Hence, researchers have on their discretion chosen a proxy for the risk-free rate. In 2000, the Korean government issued an instrument similar to TBs, called Korean Treasury Bills (KTBs). However, KTBs are not only different to TBs in terms of credibility and maturity, but also their historical time span is limited to less than 15 years.

\subsection{Estimates of the Equity Premium and a Pseudo Risk-free Rate in the U.S. Stock Market}

Table 1 of Mehra and Prescott (2003) offers a perspective on the historical estimates of the real returns on a market index and a riskless rate and their difference (i.e., the equity premium) in the U.S. stock market. We can see that the equity premium varies from 4.1 per cent to 8.4 per cent based on which financial instrument is employed to proxy for the risk-free rate. The variation in the long-term average return on a market index depends on the measurement period. In addition, the real rates for a pseudo riskless security present relatively huge discrepancies, from 0.4 to 2.9 per cent among different proxies. These two aspects of proxies for market and riskless rates (i.e., the measurement period and types of instruments) in turn result in large discrepancies in the size of the equity premium. The average yearly equity premium, for instance, is 8.4 per cent for 1926-2000, whereas it is 4.1 per cent for 1802-1990. This difference of 4.3 percentage points per annum is not a trivial figure to stock market investors. Such sizeable economic gains are clearly appreciable to most market participants trading in an exchange. Analytically, this 4.3 per cent difference can be decomposed into two parts: 1.8 per cent stems from the difference in returns on a market 
index, and 2.5 per cent is owing to the difference in real returns on a pseudo riskless security.

Interestingly, Mehra and Prescott (2003) report that the equity premium in the U.S. stock market was virtually zero for 1802-1862. During that period, however, the proxies for risk-free assets were not identical to the examination period of their 1985 paper. In terms of selecting a relatively risk-free rate as a proxy in the period from 1802 to 1871 (i.e., when there were no TBs), Siegel (1998) constructs a data set using highly rated securities with an adjustment for a default premium. Meanwhile, Mehra and Prescott (2003) use the short-term commercial paper rate as a proxy before 1920 and Treasury certificates from 1920 to 1930. Thereafter, they use short-term maturity bills as a proxy instead of longer-term notes and bonds. Considering that not all investors seek short-term investments, the characteristics of such bonds and bills compared with those of risk-bearing stocks have to be taken into account. Aside from market completeness, utility preference, and liquidity or transaction costs, Table 1 suggests that the choice for the proxy of the risk-free rate is crucial for tackling both puzzles.

\subsection{Estimates of the Equity Premium and of a Pseudo Risk-free Rate in the Korean Stock Market}

Financial environments in the Korean stock market are not significantly different from those in the U.S. stock market. As discussed, in empirical studies of the risk-free rate puzzle, several proxies have been used in different investigation periods. Kang (2008) and Kim and Hong (2008) point out that no consensus exists about a legitimate proxy as a risk-free security. Kang (2008) states that no unanimous agreement has been reached concerning which instrument is appropriate to proxy for the risk-free rate (p. 36).

Consequently,several alternative financial securities have been chosen, such as CD yields (Kim \& Hong, 2008), interest rates on time deposits (Dokko, Park, \& Cho , 2001; Choi, 2011), and a hybrid of the yields from monetary stabilization bonds and KTBs (Kang, 2008). However, none of these financial instruments is a perfect proxy. Interest rates on time deposits, for example, are not completely free from credit default risks, although the Korean government has implicitly guaranteed payment for it (Kang, 2008). Because a CD yield is higher than that of a KTB, CDs undervalue the equity premium. They are not free from credit default risks, either (Kang, 2008). Meanwhile, KTBs and monetary stabilization bonds have frequently been employed as a policy of open market manipulation. Further, these instruments do not have long time series data, and thus all may result in skewing both the equity premium and the risk-free rate puzzles.

Despite these drawbacks, Dokko et al. (2001) argue that the risk-free rate puzzle is a robust phenomenon in the Korean stock market. They find evidence that within a range of risk aversion coefficients from zero to ten, the implied risk premium satisfies the first moment restriction on the sample, but that its counterpart, the implied risk-free rate, does not. However, their argument could be based on the proxy, namely interest rate only, because no other proxies have yet been used to test the risk-free rate puzzle. Given the fact that no agreement on which one is truly representative of the risk-free rate, their argument would no longer hold. Thus, a robustness test should be carried out to check whether the phenomenon persistently prevails, in particular by conducting a sensitivity analysis for other proxies, together.

Table 1. Equity premium in the Korean financial market

\begin{tabular}{|c|c|c|c|c|c|}
\hline Data set & $\begin{array}{l}\% \text { real return on a market } \\
\text { index(mean) }\end{array}$ & $\begin{array}{l}\% \text { real interest } \\
\text { rate (mean) }\end{array}$ & $\begin{array}{c}\% \text { equity } \\
\text { premium (mean) }\end{array}$ & $\begin{array}{c}\text { Time } \\
\text { preference }\end{array}$ & $\begin{array}{c}\text { Risk } \\
\text { aversion }\end{array}$ \\
\hline $1965-2007$ & 7.21 & $3.84^{\dagger}$ & 3.37 & 1.01 & 0.69 \\
\hline (Choi) & $(33.26)$ & $(4.96)$ & $(32.29)$ & $(0.2)$ & $(0.35)$ \\
\hline $\begin{array}{l}\text { 1987.1-2008.3 } \\
\text { (Kang) }\end{array}$ & 6.70 & $1.28^{\ddagger}$ & 5.43 & - & $\begin{array}{l}0.45 \sim \\
0.71^{\Phi}\end{array}$ \\
\hline $1980-2004$ & 8.51 & $3.19^{\dagger}$ & 5.32 & $0.9925^{\pi}$ & $0.0982^{\pi}$ \\
\hline \multirow[t]{5}{*}{ (Kim-Hong) } & [36.48] & [3.09] & {$[35.72]$} & {$[0.0013]$} & {$[0.0402]$} \\
\hline & & $7.11^{\#}$ & 1.41 & $0.9903^{\text {ศึี }}$ & $0.1154^{\text {बโ์ }}$ \\
\hline & & [4.01] & [36.36] & {$[0.0014]$} & {$[0.0463]$} \\
\hline & & $4.55^{\S}$ & 3.96 & $0.9937^{\text {ศศศी }}$ & $0.1252^{\text {बाศी }}$ \\
\hline & & {$[3.84]$} & [36.39] & {$[0.0014]$} & {$[0.044]$} \\
\hline 1975-1999 & 5.91 & $3.79^{\dagger}$ & 2.12 & - & - \\
\hline (Dokko-Park-Cho) & [34.28] & [4.31] & [33.33] & & \\
\hline
\end{tabular}

Choi (2001) constructs a data set using the interest rate on a time deposit and the real return of a market index. Kang (2008) builds a data set using the real return of a market index, KOSPI, and a hybrid of the 1-year maturity yields of monetary stabilization bonds prior to the second quarter of 1995, and thereafter the 3-year maturity yield of Korean treasury bonds for a proxy as a risk-free security. Kim and Hong (2008) form a data set using the interest rate on a time deposit, an estimated CD yield, and a CD yield. The first proxy for a risk-free security is an interest rate on a 
time deposit and the second, an estimated CD yield and the third, a hybrid of the interest rate on a time deposit prior to 1991 and a CD yield post 1991. Dokko, Park and Cho (2001) establish data using an interest rate on a time deposit and a market index return, KOSPI. All variables are deflated by the Consumer Price Index. The standard error is in parentheses and standard deviation is in brackets.

$\dagger$ Interest rate on a time deposit

$\$$ Combination of the 1-year maturity yield of monetary stabilization bonds and the 3-year maturity yield of government treasury bonds

\# Estimated CD yield

$\S$ Combination of the interest rate on a time deposit (prior to 1991) plus a CD yield (post 1990)

T Quarterly data is used to estimate a risk aversion coefficient and time preference for two assets of market index and the proxy for a risk-free rate.

१ฯ Quarterly data is used to estimate a risk aversion coefficient and time preference for a market index only.

9 9 T Quarterly data is used to estimate a risk aversion coefficient and time preference for the proxy for risk-free rate only.

Table 1 illustrates four studies of the equity premium in the Korean financial market using different proxies for the risk-free rate. The second column shows the different market returns in each measurement period. These returns range from 5.91 per cent, with a standard deviation of 34.28 per cent, to 8.51 per cent, with that of 36.48 per cent. The maximum difference among the measured market returns is 2.3 per cent (7.21 minus 5.91), while the pseudo risk-free rates vary from 1.28 per cent to 5.49 per cent. The maximum difference, 4.21 per cent, which is, in fact, larger than that of market returns. Compared with the equity returns and risk-free rate in the U.S. financial market, those in the Korean financial market are approximately 0.8 per cent and 2.5 per cent larger, respectively. Further, given that the average historical equity premium ranges from 1.41 per cent to 5.43 per cent in the Korean financial market, clearly, the size of the equity premium depends considerably on the proxies used as a counterpart to equity returns, apart from the measurement period of returns on the market index.

In the previous studies, Kang (2008) reports a minimum mean of the real interest rate of 1.28 per cent. So, it leads to the largest equity premium among the studies. By contrast, Dokko et al. (2001) report an average real interest rate of 3.79 per cent, which, in turn, produces the smallest equity premium. From these preliminary statistics, the size of the pseudo risk-free rate turns out to be strongly associated with the equity premium puzzle; therefore, we posit that the choice of a proxy is a key determinant of the risk-free rate puzzle.

\section{Models}

We start with the rational model to assess how equilibrium models generate the implied returns based on time series data and to explain how sensitive the implied returns are according to each proxy. In Lucas's (1978) fruit-free economy, investors aim to maximize expected utility subject to capital budget constraints. From this economy, we can induce the equilibrium interest rate in an environment of the utility optimization of rational expectation agents.

$$
M A X E_{t} \sum_{h}^{\infty} \delta^{h} U\left(C_{t+h}\right)
$$

and

$$
\tilde{W}_{t+1}=\left(1+\tilde{R}_{p, t+1}\right) \cdot\left(W_{t}-C_{t}\right)
$$

$W_{t}$ is wealth at time $t, \tilde{R}_{p, t+1}$ is a portfolio comprising the risky, $R_{i, t+1}$, and the riskless asset is $R_{f}$. In short, $1+\tilde{R}_{p, t+1}=\omega_{t}\left(\tilde{R}_{i, t+1}-R_{f, t+1}\right)+\left(1+R_{f, t+1}\right)$ with a weight of equities, $\omega$. The first-order condition describes the optimal portfolio and consumption rules of the agent. The two first-order conditions with respect to $C_{t}$ and $C_{t+1}$ yield the following equation, namely the Euler equation. 


$$
\frac{\partial U\left(C_{t}\right)}{\partial C_{t}}=\delta E_{t}\left\{\left(1+R_{i, t+1}\right) \frac{\partial U\left(C_{t+1}\right)}{\partial C_{t+1}}\right\} .
$$

This equation states that the marginal cost at time $t$ on the left-hand side equals the expected marginal benefit at time $t+1$ on the right-hand side. Hence, we can derive the implied risk-free rate from the Euler equation by using a functional form of the time-additive preference, $U(C)=\frac{C^{1-\gamma}-1}{1-\gamma}$, using a moment-generating function technique, after substituting the two conditions into the Euler equation.(Note 2)

$$
\ln \left(1+R_{f, t}\right)=-\ln \delta+\gamma \cdot \mu_{c}-\frac{\gamma^{2}}{2} \sigma_{c}^{2} .
$$

$\mu_{c}$ is the expected growth rate in consumption, $\sigma_{c}^{2}$ is its variance, and $\gamma$ is the relative risk aversion coefficient.

This expected risk-free return based on separable preferences is high if the expected consumption growth rate is high, while it is low if its variance is large. The tradeoff between expected returns and the variance in consumption growth balances the price of the risk-free asset.

\subsection{Movements in Interest Rate and State Variables}

To illustrate the real-world behavior of the long-term interest rate before it is matched up with the theoretical risk-free rate, Panel A in Figure 1 presents the general time trends of the three macro-financial indicators among interest rates, consumption growth, and inflation (measured by the Consumer Price Index (CPI)). In the 1970s, inflation sharply rose from approximately 11 per cent to 16 per cent following two oil shocks that attacked the world economy. These persistent impacts lasted until the early 1980s in the Korean economy and then drastically declined until 1992. Accordingly, the real interest rate started to depreciate severely in 1974, reaching a trough in 1981 before rapidly rising to 6 per cent in 1975. Indeed, real interest rates on time deposits were severely depreciated by the hyperinflation rate, although nominal rates during the entire sample period peaked at that time. (Note 3)

\section{Panel A}

Interest rate, consumption growth, and inflation

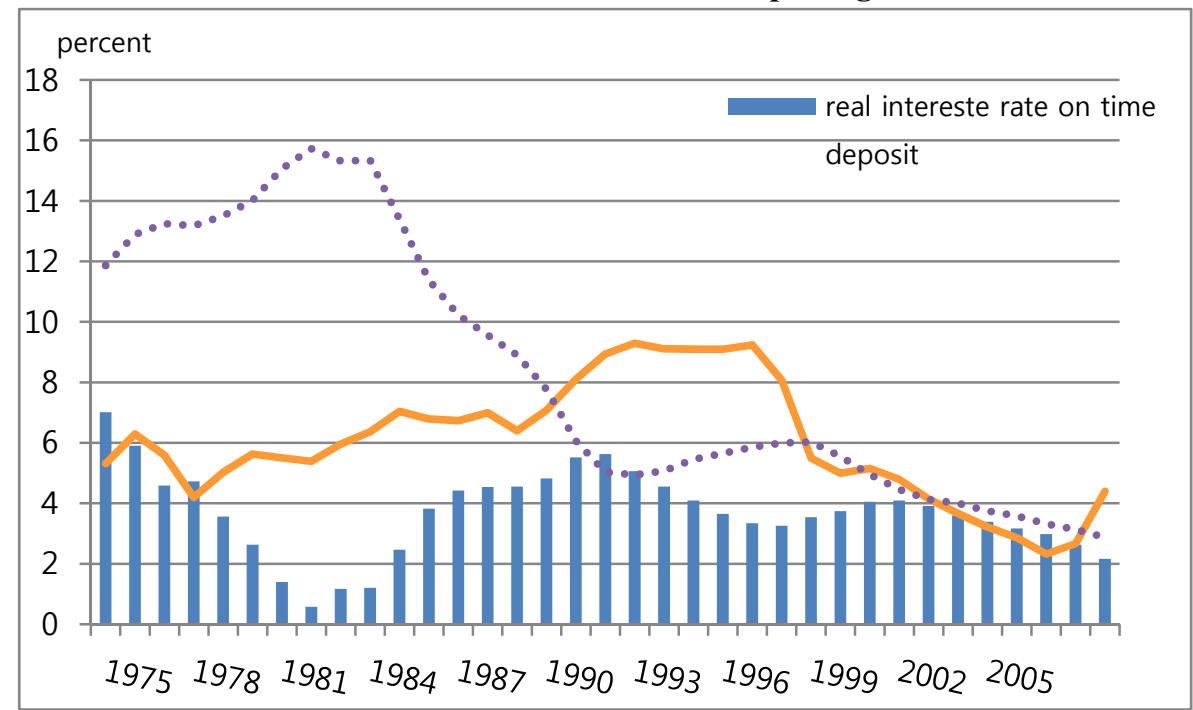




\section{Panel B Correlations of interest rate and consumption growth}

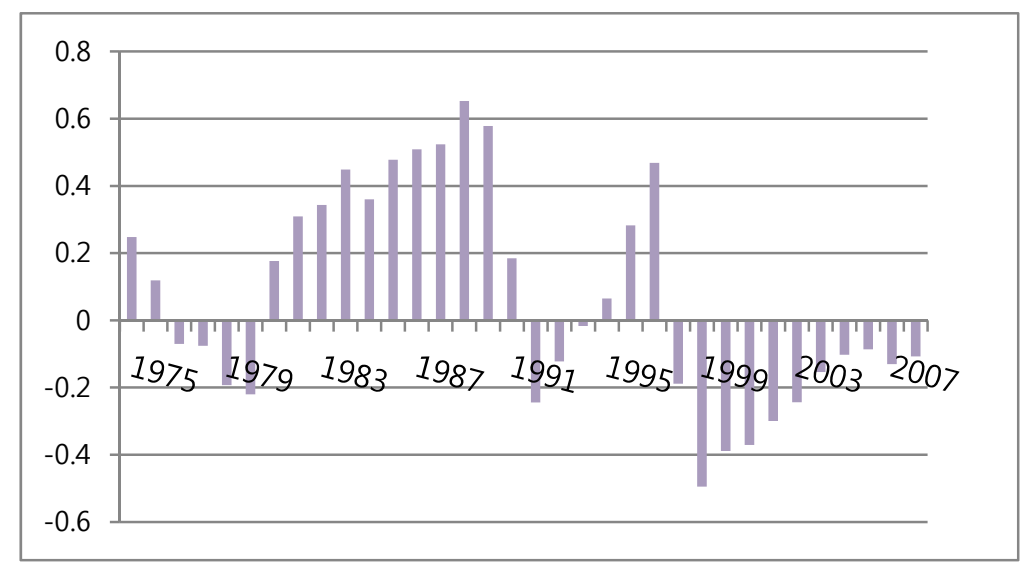

Figure 1. Interest rate, consumption growth, inflation, and correlation

The data covers the period from 1965 to 2008. In Panel A, the solid bar indicates 10-year overlapping moving average of interest rates on time deposits. The solid line indicates 10-year overlapping moving average of the log per capita consumption growth rate and the dotted line indicates 10-year overlapping moving average of the log inflation rate as measured by the CPI. In Panel B, on the other hand, the bar line indicates the correlation of the real interest rate on time deposits and real per capita consumption growth rate. All indicators except for CPI are deflated by the logarithmic change in the CPI, which is based on the won in 2005.

In the meantime, consumption grew following the end of hyper-nominal interest persistence and stayed very high during the mid-1990s before declining. In other words, Panel A in Figure 1 suggests that the asset prices of interest rates fluctuated and that they were largely influenced by inflation. Real consumption growth fluctuated over time as well. If interest rates, say, were a function of state variables, such as consumption growth and inflation behaved as shown in Panel A in Figure 1, the implied interest rate would be better explained by equation (4). Panel B in Figure 1 shows the 10-year overlapping moving average correlation between interest rates and consumption. This correlation declined before 1980 and then turned dramatically upward until 1990. It dropped down to less than -0.2. It underwent the same cycle again in the next eight years. This historical behavior illustrates how closely related consumption growth and interest rates are over time.

\subsection{Matching the Moments of the Risk-free Rate}

Previous studies focus on an equilibrium process that generates returns and simply compare the magnitude of implied returns with the mean of observed returns (Mehra\& Prescott, 1985, 2003; Weil, 1989; Hung, 1994; Bansal\&Yaron, 2004). Thus, a significance test is carried out by checking whether implied returns are greater than the historical average of the risk-free rate. This comparison test, however, lacks a precise statistical operation. To reliably infer and obtain consistent results, we thus generate the implied risk-free rate series from the model, assuming a consumption growth distribution $\Delta \ln c_{t+1} \sim N\left(\mu_{c}, \sigma_{c}^{2}\right)$. Specifically, we first replace expected consumption growth, $\mu_{c}$, with the actual time series consumption growth, $\Delta \ln c_{t+1}$, calculated from the data set constructed from the reported source of each aforementioned study, keeping constant the assumption of an estimated variance in consumption growth, $\sigma_{c}^{2}$. Then, we generate a series of implied risk-free rates. This technique has two advantages in testing the hypothesis of the risk-free rate puzzle. One is that it helps generate the implied risk-free rate series from theoretical models and thus ameliorate the comparability of outcomes with observed returns regarding whether they are statistically different. This can be carried out using the t-test rather than merely comparing the discrepancy between the two means, as most previous studies did. The other one is that the assumption of the homoscedasticity of consumption growth, despite the diverse types of proxies for the risk-free rate, facilitates a quantitatively in-depth analysis with regard to how sensitive the risk-free rate puzzle is across those proxies. 
Table 2. Statistics of different proxies for a risk-free security and consumption growth

\begin{tabular}{ccccccc} 
Panel A & \multicolumn{7}{c}{ Proxy for risk-free rate } \\
\hline & $\begin{array}{c}\text { Consumption } \\
\text { growth }\end{array}$ & ECD & FCD & Kang & Choi & Dokko \\
\hline $\begin{array}{c}\text { Mean } \\
\text { Standard } \\
\text { deviation }\end{array}$ & 5.85 & 5.40 & 4.75 & 5.38 & 4.00 & 3.12 \\
\hline Panel B & 6.39 & 3.34 & 3.79 & 3.08 & 4.34 & 3.41 \\
\hline $\begin{array}{c}\text { Implied } \\
\text { Mean }\end{array}$ & Time additive preference \\
\hline Difference & 4.11 & 3.41 & 3.19 & 2.94 & 3.10 \\
\hline T test & 1.29 & 1.34 & 2.19 & 1.06 & 0.02 \\
\hline Panel C & $7.84^{* * *}$ & $9.56^{* * *}$ & $3.34^{* * *}$ & 1.25 & 0.08 \\
\hline $\begin{array}{c}\text { Implied } \\
\text { Mean }\end{array}$ & External habit ratio model & \\
\hline Difference & 10.7 & 10.29 & 6.60 & 5.3 & 5.29 \\
\hline T test & -5.3 & -5.54 & -1.22 & -1.3 & -2.17 \\
\hline
\end{tabular}

ECD is the data set of an estimated CD yield for 1987 to 2008. ECD is calculated by subtracting the average spread of 0.58 per cent ${ }^{b}$ from the yield of AA- credit rating corporate bonds (3 years to maturity) from 1987 to 1990, plus the time series of CD yields afterwards. FCD is a hybrid of the interest rate on time deposits to 1991 from 1987, and the CD yields afterwards. Dokko and Choi have the identical proxy, the interest rate on time deposits, as a relatively risk-free security for 1975 to 2008 and for 1965 to 2008, respectively. Kang's data set is a hybrid of the yield of monetary stabilization bonds (1 year to maturity) from 1987 to 1995 , and thereafter, that of KTBs (3 years to maturity) up through 2008. All statistics are deflated by the natural logarithm growth of the CPI, which is based on the 2005 won. $*, * *, * * *$ indicate significance levels of 10,5 , and 1 per cent with two tails, respectively. ${ }^{\text {b See }}$ footnote 7 in Kim and Hong (2008).

For the sake of comparability, we choose an annual data instead of a quarterly data frequency. We collect time series interest rates on time deposits for 1995 to 2008, while for 1963 to 1995 we collect data from Monthly Statistics, published by the Bank of Korea. At the beginning of the 1960s and 1970s, the interest rate was announced irregularly. Thus, we presume that if no annual interest rate was announced during the examination period, the previous yearly interest rate continued until a new announcement in the financial market. When interest rates are announced several times in a year, we weight them by time span. When interest rates on time deposits are presented as a range, we adopt the minimum value. The CPI comes from ECOS, the database of the Bank of Korea, for 1965 to 2008. In addition, we obtain yields of monetary stabilization bonds (364 days to maturity) for 1987 to 1995 and KTBs (three years to maturity) for 1996 to 2008.
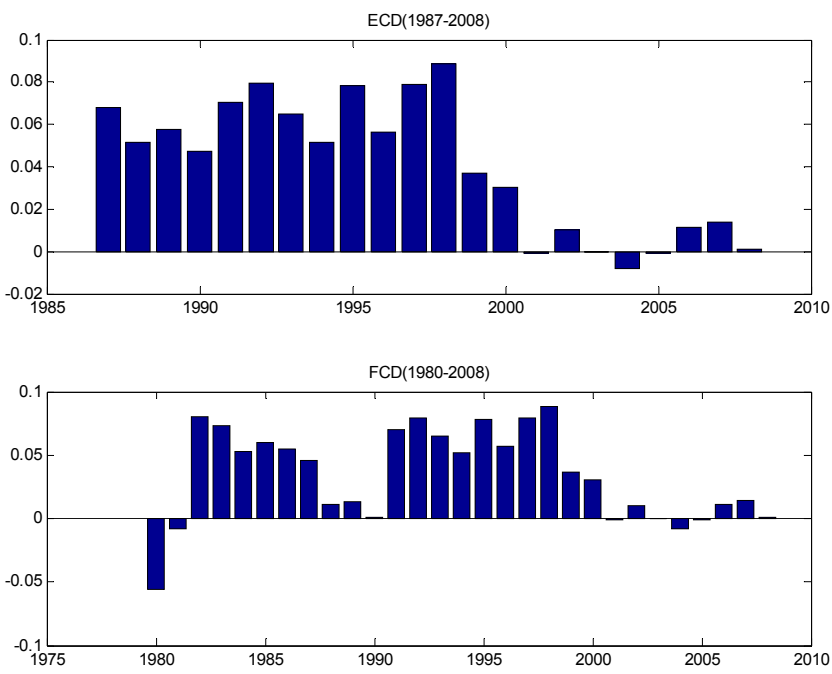

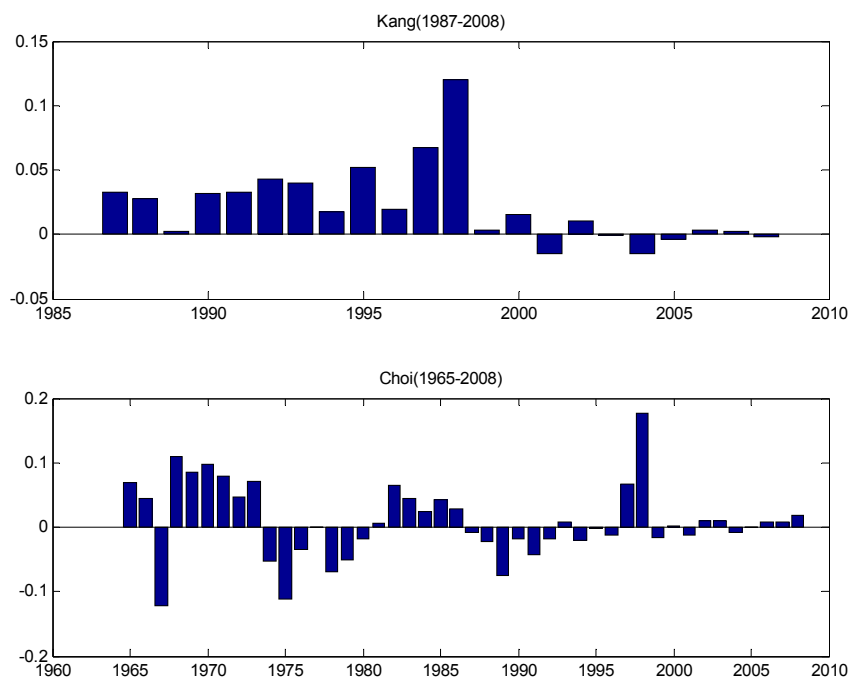

Figure 2. Discrepancy in risk-free rates using a time additive preference

The bars indicate the discrepancy between observed returns and risk-free rates generated by time-separable preferences, equation (2), pre-specifying a set of time preferences and risk aversion of $(0.9932,0.1252)$ for both the ECD and FCD data sets, and $(0.9932,0.45)$ and $(1.01,0.69)$ for hybrid (Kang) and interest rate (Choi), respectively. See the detailed description for Table 1 concerning data characteristics.

We also construct yields of AA- corporate bonds (three years to maturity) from 1987 to 1990 and CD yields (91 days to maturity) for 1991 to 2008. All these financial instruments come from ECOS. Finally, average monthly consumption for urban households for 1965 to 2008 comes from KOSIS, the database of Statistics Korea.Panel A in Table 2 presents the different proxies for a risk-free security and consumption growth up to 2008. By comparing these statistics with those in Table 1, we find that real interest rates on time deposits have recently been declining. For instance, the average interest rate for 1975 to 1999 is 3.79 per cent (third column in Table 1), whereas for the extension period to 2008, it drops to 3.12 per cent (the rightmost column in Panel A of Table 2), resulting in the smallest mean with a standard deviation of 3.41 percent. By contrast, the estimated certificate of deposit (ECD) is the largest mean value of 5.4 per cent per annum with a standard deviation of 3.34 per cent. Interestingly, even though consumption growth has drastically declined recently, as shown in Panel A in Figure 1, average consumption growth is higher than the averages of any other instruments during the whole sample period, and its volatility also is the greatest relative to other variables. Hence, high consumption volatility relative to that in the U.S. financial market (approximately 1 per cent) could play a major role in solving the risk-free rate puzzle.The graphs in Figure 2 show the difference between observed returns and the implied risk-free rates generated by time-separable preferences, using equation (4) with some pre-specified parameters for risk aversion and time preference, as indicated in Table 1. The first three graphs of ECD, FCD (i.e., CD yields with interest rates on time deposits), and Kang show that observed returns are generally larger than the implied risk-free rates over time. These graphs suggest that the model can generate risk-free rates that are observable in the mundane economy, but only in the special circumstances of a risk aversion of less than one.

However, the last graph is not as clear as the others. Panel B in Table 2 suggests that time-separable preferences generate risk-free rates that are less than the means of observed returns. Of the means of each implied risk-free rate calculated using equation (4), ECD is the largest implied mean, producing a difference of 1.29 per cent between the mean of the observed data and that of the implied risk-free rate at a significance level of 1 per cent. Kang's hybrid proxy also creates the largest difference of 2.19 per cent with a statistical significance of 1 per cent, while Dokko et al.'s data set generates a mean of 3.1 per cent with a difference of 2 basis points, resulting in statistical insignificance. This means that the implied risk-free rate using time-separable preferences matches the first moment of the observed interest rate only as long as the risk aversion is less than one. In the finance literature, however, reasonable risk aversion is deemed to range from one to ten (Friend \&Blume, 1975; Kydland\& Prescott, 1982). For this reason, we analyze the typical case of risk aversion using calibration. The graphs in Figure 3 offer a more extensive case that complements the case of a risk aversion of less than one.

The graphs in Figure 3 plot the means of the implied risk-free rates of each proxy against risk aversions of one to ten and time preferences of 0.98 to 1.02 in increments of 0.01 using time-separable preferences. By calibrating via the means of ECD, the mean of the implied risk-free rate increases along with relative risk aversion but decreases across time preferences at the same degree of risk aversion. From a statistical viewpoint, most means of the implied 
risk-free rate are higher than those of observed returns across time preferences: these are accompanied by more than four fifths of mean differences that are statistically significant at a level of 1 or 5 per cent.(Note 4) This suggests that the model that proxies ECD does not satisfy the first moment restriction of observed returns. In addition, note that these results are contrary to those for a risk aversion of one, namely none meets the first moment restriction. Likewise, the same inference can be drawn for other types of proxies. In other words, most means of the implied risk-free rates for each proxy increase with increasing risk aversion and do not completely satisfy the moment restriction.(Note 5) These results are consistent with the findings concerning the incapability of a time-separable model with a risk aversion over one (Weil, 1989; Constantinides\&Ferson, 1991; Ferson\& Harvey, 1992; Kocherlakota, 1996). We compare these results with those generated via an external habit ratio model in section 3.3.

\subsection{An Alternative Model for Solving the Risk-free Rate Puzzle}

Because of evidence that a time-separable utility cannot solve these two puzzles, habit-based models reemerge as an alternative solution for the puzzles observed in a mundane economy (Constantinides, 1990; Abel, 1990; Campbell \& Cochrane, 1999). In this paper, we accommodate an external habit ratio model as an alternative to explain the puzzle, which is capable of characterizing the particular behavior of consumers. In other words, it reflects the past consumption of consumers by tracking their behavior via aggregate consumption rather than at an individual level. In short, the time-nonseparable preferences of habit formation make marginal utility more volatile than time-separable preferences do, which is desirable for our research goal. Further, models based on habit formation incorporate how consumers' consumption adjusts to changes in asset prices and/or habit persistence, thus better explaining the risk-free rate puzzle (Parker \& Julliard, 2005; Constantinides, 1990; Campbell \&Constantinides, 1999).
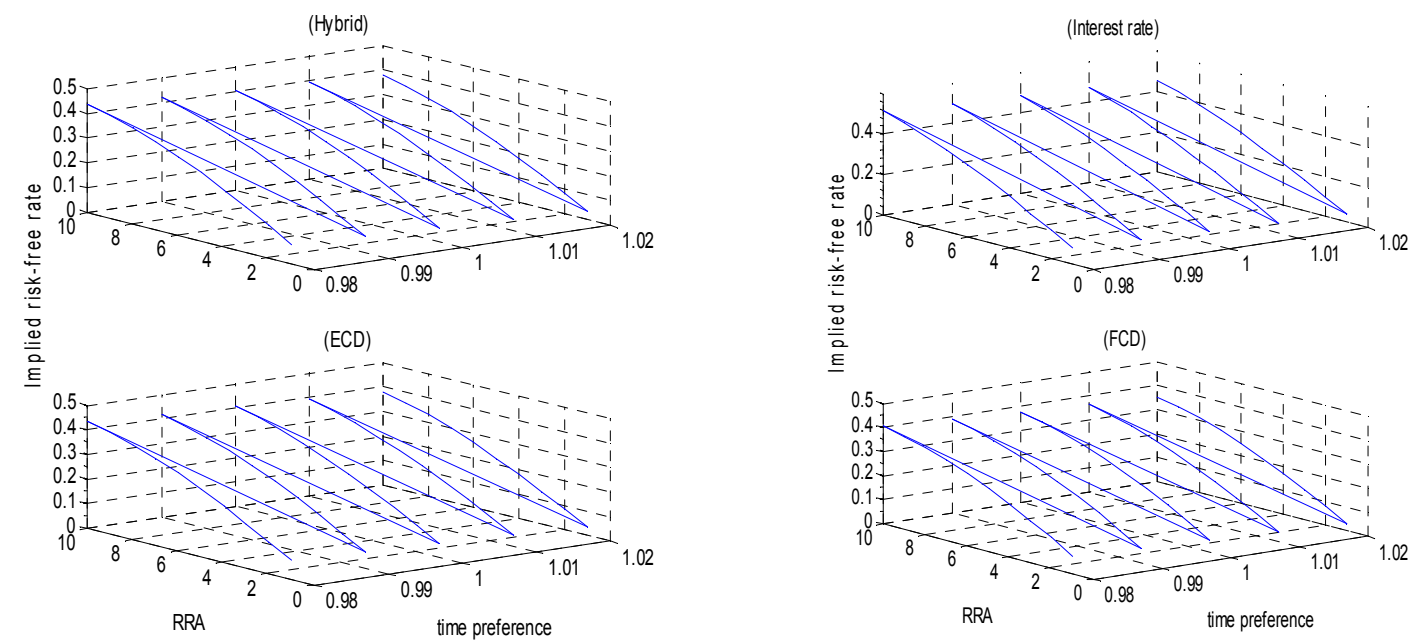

Figure 3. Implied risk-free rate generated by time-separable preferences

This figure shows the implied risk-free rate using equation (4) along with risk aversion ranging from one to ten and a time preference of 0.98 to 1.02 using the ECD and Hybrid proxies, respectively. ECD is calculated by subtracting the average spread of 0.58 per cent from the yield of AA- credit rating corporate bonds (three years to maturity) from 1987 to 1990, and adding the time series of CD yields up to 2008. Hybrid is a combination of the one-year maturity yields monetary stabilization bonds prior to the second quarter of 1995 and thereafter the three-year maturity yields KTBs. Interest rate is a rate on a time deposit. FCD is a hybrid of the interest rate on time deposits to 1991 from 1987 , and the CD yields afterwards.

For agents who display external ratio habit formation, $U(C, X)=\frac{(C / X)^{1-\rho}-1}{1-\rho}$, the implied risk-free rate (Note

6) generated by the model is,

$$
\ln \left(1+R_{f, t}\right)=-\ln \delta+\rho \cdot \mu_{c}-\kappa \cdot(\rho-1) \cdot \square c_{t}-\frac{\rho^{2}}{2} \sigma_{c}^{2} .
$$

$\rho$ is risk aversion and $\kappa$ governs the degree of time-nonseparability. Compared with equation (4), equation (5) has an additional term, $\kappa \cdot(\rho-1) \cdot \square c_{t}$, which functions as a reflector that mirrors the level of past aggregate consumption if $X$ at time $t$ is assumed to follow past aggregate consumption at time $t-1$, i.e., $X_{t}=C_{t-1}^{\kappa}$. The 
assumption underlying this equation states that the change in past consumption at $t-1$ propels the marginal utility of consumption at time $t$ upward or downward. The common feature of the two models of time-separable preferences and external habit formation is that their equity premiums can be generated by the same term, namely risk aversion multiplied by covariance in risky asset returns with consumption growth. This characterization, aside from the equity risk premium, enhances the comparability of interest rate behavior between the two models.

As a counterpart to Figure 2, the graphs in Figure 4 show the difference between the observed returns of each proxy for the pseudo risk-free rate and the implied risk-free rate, using equation (5) equipped with pre-specified parameters of risk aversion and time preferences in the case of $\kappa=1$. The first three graphs of ECD, FCD, and hybrid show that implied returns are generally greater compared with observed returns. This visual judgment suggests that the effect of the habit model on returns is comparable with that of time-separable preferences. The last graph switches from a negative to a positive sign or vice versa several times, drawing no clear distinction. Panel $\mathrm{C}$ in Table 2 shows the statistical results, supporting the explanation of these graphs, namely all implied risk-free rates are sufficiently large relative to the means of observed returns.
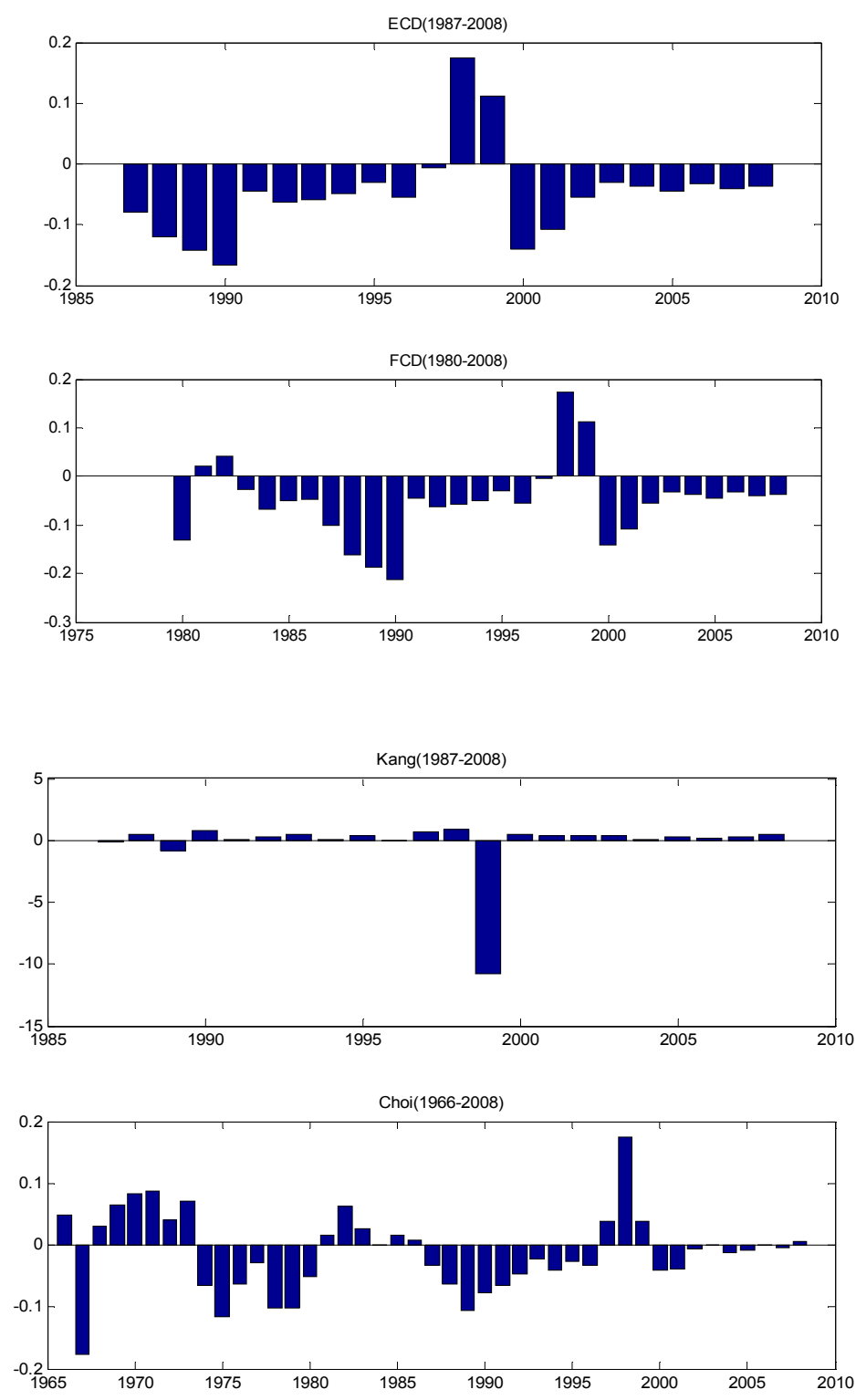

Figure 4. Discrepancy in risk-free rates using an external habit ratio model 
The bars indicate the discrepancy between observed returns and risk-free rates generated by an external habit ratio model, equation (3) pre-specifying a set of time preferences and risk aversion of $(0.9932,0.1252)$ for the ECD and FCD data sets and of $(0.9932,0.45)$ and $(1.01,0.69)$ for hybrid (Kang) and interest rate (Choi) in the case of $\kappa=1$. See the detailed description for Table 1 concerning data characteristics.

This implies that in the special case of $\kappa=1$, together with a low risk aversion of below one, the external habit ratio model cannot generate a risk-free rate that satisfies the first condition for solving the risk-free rate puzzle. These results are in sharp contrast with those that time-separable preferences yield at the same order of risk aversion. However, these results hold as long as that the risk aversion is below one. In order to understand consumer behavior in the context of a reasonable attitude toward risk, we now assess the variation in the implied risk-free rate by changing the risk aversion from one to ten. Panels A and B in Table 3 show the average implied risk-free rate using ECD and Hybrid as in equation (5). With the degree of time-nonseparability fixed at 0.7 , the average implied risk-free ratesof both mostly decreasewith increasing risk aversion. Further, as time preferences move to a higher rate, smaller implied values appear. Anyway, some implied risk-free rates meet the first moment restriction of observed returns along with specific risk aversion parameters. That is, the bold, italicized numbers indicate the economic values, together with the $t$ value of the difference in the next right column. To provide a concrete illustration, for a time preference of 1.01, risk aversions of five, six, seven, and eight in Panel A can solve the risk-free rate puzzle.

Table 3. Implied risk-free rate from external habit ratio model

Panel A: ECD

\begin{tabular}{|c|c|c|c|c|c|c|c|c|}
\hline \multirow[b]{3}{*}{$\begin{array}{c}\text { Risk } \\
\text { aversion }\end{array}$} & \multicolumn{8}{|c|}{ Time preference } \\
\hline & \multicolumn{2}{|c|}{0.98} & \multicolumn{2}{|l|}{0.99} & \multicolumn{2}{|c|}{1.00} & \multicolumn{2}{|l|}{1.01} \\
\hline & $\begin{array}{c}\text { Mean of } \\
\text { implied } R_{f}\end{array}$ & t-value & $\begin{array}{c}\text { Mean of } \\
\text { implied } R_{f}\end{array}$ & t-value & $\begin{array}{c}\text { Mean of } \\
\text { implied } R_{f}\end{array}$ & t-value & $\begin{array}{c}\text { Mean of } \\
\text { implied } R_{f}\end{array}$ & t-value \\
\hline 10 & -0.22 & 0.37 & -1.23 & 0.43 & -2.22 & 0.50 & -3.19 & 0.56 \\
\hline 9 & 2.27 & 0.23 & 1.24 & 0.30 & 0.22 & 0.38 & -0.77 & 0.45 \\
\hline 8 & 4.4 & 0.09 & 3.34 & 0.17 & 2.31 & 0.26 & 1.3 & 0.34 \\
\hline 7 & 6.13 & -0.05 & 5.06 & 0.42 & 4.01 & 0.14 & 2.98 & 0.23 \\
\hline 6 & 7.46 & -0.20 & 6.37 & -0.09 & 5.31 & 0.02 & 4.27 & 0.13 \\
\hline 5 & 8.36 & -0.36 & 7.26 & -0.22 & 6.19 & -0.08 & 5.14 & 0.05 \\
\hline 4 & 8.82 & -0.53 & 7.72 & -0.36 & 6.64 & -0.18 & 5.59 & -0.01 \\
\hline 3 & 8.84 & -0.73 & 7.74 & -0.49 & 6.66 & -0.25 & 5.6 & -0.02 \\
\hline 2 & 8.41 & -1.01 & 7.32 & -0.63 & 6.24 & -0.25 & 5.19 & 0.12 \\
\hline 1 & 7.54 & -1.54 & 6.46 & -0.72 & 5.39 & 0.10 & 4.35 & 0.91 \\
\hline \multicolumn{9}{|c|}{ Panel B: Hybrid } \\
\hline 10 & -1.24 & 0.48 & -2.24 & 0.57 & -3.21 & 0.65 & -4.17 & 0.73 \\
\hline 9 & 1.32 & 0.31 & 0.3 & 0.40 & 0.71 & 0.49 & -1.69 & 0.58 \\
\hline 8 & 3.52 & 0.13 & 2.48 & 0.23 & 1.45 & 0.34 & 0.45 & 0.44 \\
\hline 7 & 5.34 & -0.05 & 4.27 & 0.07 & 3.23 & 0.18 & 2.21 & 0.3 \\
\hline 6 & 6.75 & -0.25 & 5.67 & -0.11 & 4.62 & 0.03 & 3.58 & 0.17 \\
\hline 5 & 7.74 & -0.45 & 6.65 & -0.28 & 4.54 & 0.05 & 4.54 & 5.19 \\
\hline 4 & 8.3 & -0.69 & 7.2 & -0.47 & 5.08 & -0.04 & 5.08 & -0.04 \\
\hline 3 & 8.41 & -0.97 & 7.32 & -0.68 & 5.19 & -0.09 & 5.19 & -0.09 \\
\hline 2 & 8.08 & -1.38 & 6.99 & -0.92 & 4.87 & -0.00 & 4.87 & -0.00 \\
\hline 1 & 7.32 & -2.04 & 6.23 & -1.14 & 4.13 & 0.62 & 4.13 & 0.62 \\
\hline
\end{tabular}

Panel A shows the risk-free rate generated from the external habit ratio model using an estimated CD yield for 1987 to 2008 , which is calculated by subtracting the average spread of 0.58 per cent from the yield of AA- credit rating corporate bonds ( 3 years to maturity) from 1987 to 1990, plus the time series of CD yield afterwards that time. Panel $\mathrm{B}$ shows the risk-free rate generated from the external habit ratio model, combining the yield of monetary stabilization bonds (1 year to maturity) from 1987 to 1995, and thereafter, KTBs (3 years to maturity) through 2008. $\kappa$, the degree of time-nonseparability, is fixed at 0.7 . The mean of implied $\mathrm{R}_{\mathrm{f}}$ is a return that exponentiates the mean of the implied risk-free rate from the model, shown in eq. (3). The t-value is a test statistic on the difference between observed returns and implied returns from the model, shown in eq. (3). *,**,*** indicate significance at the 10,5 , and 1 per cent levels with two tails, respectively. The t-values at significance levels of 1,5 , and 10 per cent from a two-tailed test with a degree of freedom of 21 are $2.83,2.08$, and 1.72 , respectively. 
The model produces means of the implied risk-free rate 5.14, 4.27, 2.98, and 1.3, respectively, none of which is statistically significant. In other words, compared with the statistic of ECD in Panel A of Table 2, 5.40, the generated values are below the mean of the proxy, ECD. We also see that some combinations of risk aversion and time preference offer solutions to the problem in other time preference columns. For instance, if time preference is fixed at 0.98 , the model generates 4.4 for risk aversions of eight, and 2.27 of nine, respectively. In the meanwhile, some of the generated values in Panel B satisfy the moment restriction: risk aversions of five to nine with time preference of 1.01 generate the means below the average of 5.38, puzzling out the problem. In much the same vein, when the degree of time-nonseparability, $\kappa$, is 0.9 , other combinations of time preferences and risk aversions for either of ECD or Hybrid give rise to a chance that is able to puzzle out the problem, in a sense that the first moment condition is met (Note 7). Coincidently, similar results are obtained if the hybrid proxy is used. Panel B presents the implied values with the same parameters as used in Panel A. Along with risk aversion of six to eight, implied risk-free rate is dwindling, maintaining the first moment restriction.

Panel A in Figure 5 presents the loci of the implied risk-free rate calibrated using equation (5). At a time preference of 0.98 , small sets of relative risk aversion and the degree of time-nonseparability, $\kappa$, make the implied risk-free rate generated by a proxy, hybrid, meet the first moment of observed returns; in particular, the high degree of time-nonseparability and the modest risk aversion levels of four, five, and six. These findings are all supported by statistical results. The stars in each graph present the loci of the first moment that meets the restriction. In other words, no significant difference between observed and generated values is found. When the time preference moves to a higher rate, 1.01 or 1.02 , more sets of $\kappa$ and risk aversion satisfy the mean restriction, which means that moderate risk aversion levels over the whole of $\kappa$ make the external habit model capable of generating an implied risk-free rate that matches the series of observed returns on average. In short, the graphs of the hybrid yields coincide with the interpretation created by the proxy of ECD. Panel B in Figure 5 shows the loci of the theoretical risk-free rate using FCD. The graphs in Figure 5 are similar to those of the hybrid proxy, although there are slight differences in that the implied risk-free rate using the FCD proxy has more sets of stars compared with the hybrid proxy across time preferences.

By contrast, when the interest rate is proxied, no values of risk aversion combined with any class of time preference satisfy the means of observed returns between the ranges of $\kappa=0.1$ and $\kappa=0.9$ as discussed in section 3.2 (Note 8). To sum up, while the time-separable preferences fail to offer a solution to the risk-free rate puzzle unless the risk aversion is less than one, the external habit ratio model provides at least a partial solution within reasonable ranges of risk aversion.

\section{Panel A: Hybrid}

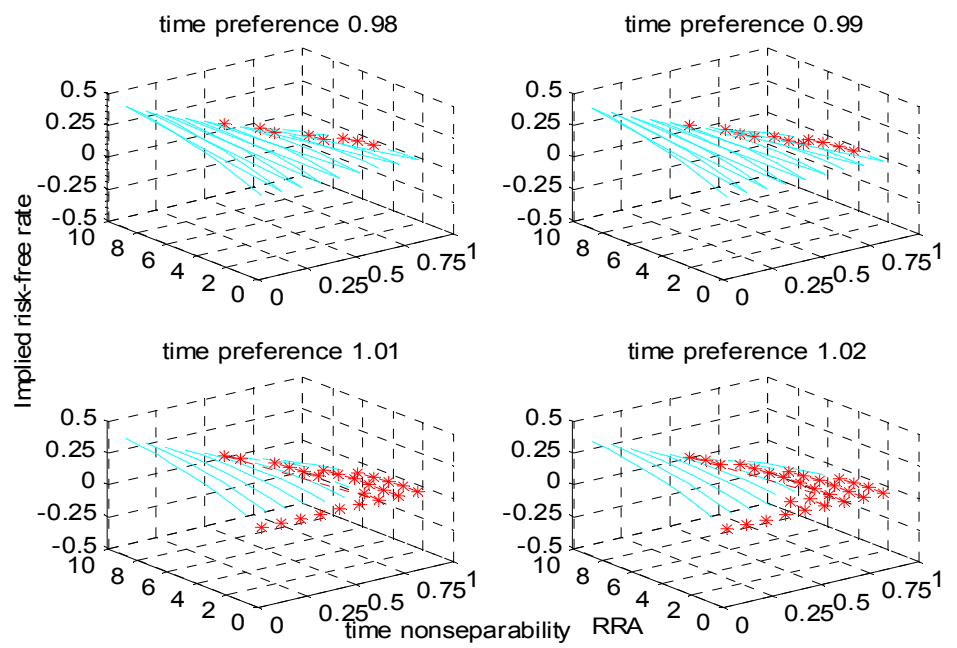

Figure 5. Implied risk-free rate generated from the external habit ratio model

\section{Concluding Remarks}

This paper puts an emphasis on the feasible devices with the force of habit and the choice of financial instruments free of risk and shows how those work out in unraveling the enigma. As a consequence, we elicit economically significant findings into the puzzle. 
For the most part, we show that an external habit ratio model against a time-separable utility can provide a partial solution to the risk-free rate puzzle within reasonable parameterizations that govern the utility function and risk aversion. Specifically, using an external habit ratio model, proxies such as ECD, FCD, and KTB combined with monetary bonds make the implied risk-free rate derived from each proxy sample capable of matching the first moment restriction in reasonable ranges of risk aversion, except for the proxy of interest rates on time deposits. As a matter of fact, we come to a tentative conclusion that the risk-free rate puzzle is not free from the choice of a proxy for risk-free asset in the Korean stock market as in the U.S. stock market. Secondly, the feasible solution thus stems from the trait of the external habit ratio model that mirrors the variation in past consumption in spite of heterogeneous data attributes. Thirdly, it turns out that the degree of time-nonseparability plays a major role in lowering the implied interest rate so that it eventually makes the external habit ratio model able to generate the implied interest rate equal to or below the observable returns in the financial market. That is, time-nonseparability as well as the force of habit offers a key solution in unraveling the risk-free rate puzzle. On the contrary, when time-separable preferences are utilized, no solution to the puzzle can be provided without restricting the risk aversion ratio to less than one.

\section{Panel B: FCD}

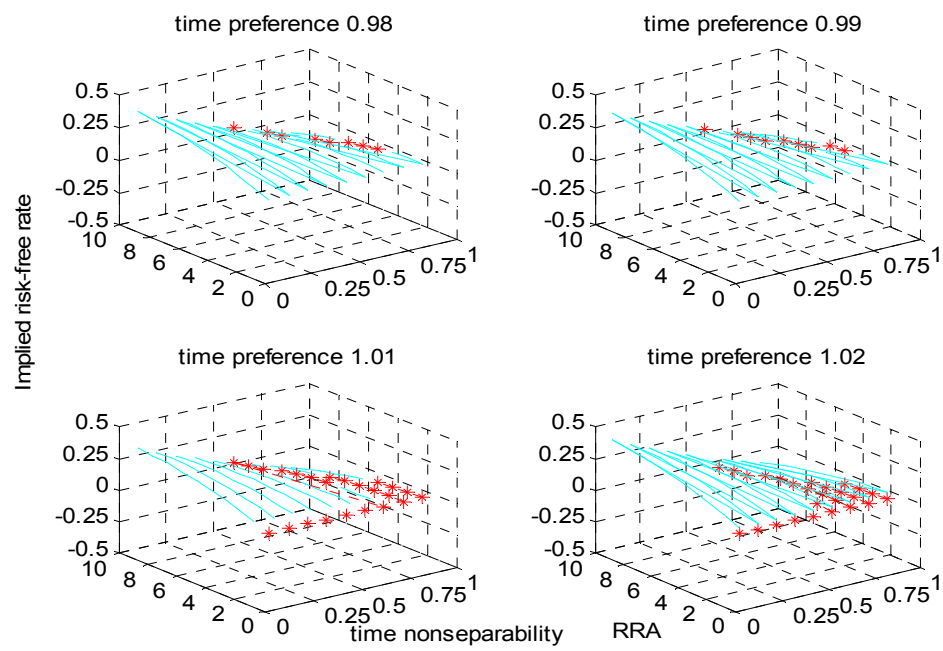

The graphs in Panel A in Figure 5 plot the implied risk-free rate using the hybrid proxy in line with equation (5) along with risk aversion ranging from one to ten and the degree of time non-separability from 0.1 to 0.9 for each rate of time preference from 0.98 to 1.02 in increments of 0.01 except for the rate of 1.00 . Hybrid is computed by subtracting the time average spread of 0.58 per cent that Kim and Hong(2008) suggest from the yield of AA-credit rating corporate bonds matured in three years for the period 1987 to 1990. The graphs in Panel B plot the implied risk-free rate by means of FCD using equation (5) with the same parameter restrictions. FCD in Panel B is the hybrid of interest rate on time deposits from 1987 to 1991 and CD yields from 1991 up to 2008.

\section{References}

Abel, A. (1990). Asset prices under habit formation and catching up with the Joneses. American Economic Review, $80,38-42$.

Abel, A. (1999). Risk premia and term premia in general equilibrium. Journal of Monetary Economics, 43, 3-33. http://dx.doi.org/10.1016/S0304-3932(98)00039-7

Bansal, R., \& Yaron, A. (2004). Risks for the long run: A potential resolution of asset pricing puzzles. Journal of Finance, 49, 1481-1509. http://dx.doi.org/10.1111/j.1540-6261.2004.00670.x

Barro, R. (2006). Rare disasters and markets in the twentieth century. QuarterlyJournal of Economics, 121, 823-826. http://dx.doi.org/10.1162/qjec.121.3.823

Campbell, J., Lo, A., \& Mackinlay, C. (1997).Econometrics of financial market. New Jersey, NJ: Princeton University Press.

Campbell, J., \& Cochrane, J. (1999). By force of habit: A consumption-based explanation of aggregate stock market behavior. Journal of Political Economy, 107, 205-251. http://dx.doi.org/10.1086/250059

Cecchetti, S., Lam, P., \& Mark, N. (1993). The equity premium \&the risk-free rate: matching the moments. Journal 
of Monetary Economics, 31, 21-45. http://dx.doi.org/10.1016/0304-3932(93)90015-8

Choi, W. (2011). The habit formation and the equity premium puzzle in case of Korea. Korean Journal of Financial Studies, 40, 261-285.

Cochrane, J. (1997). Where is the market going? Uncertain facts and novel theories. Federal Reserve Bank of Chicago Economic Perspectives, 21, 3-37.

Constantinides, G. (1990). Habit formation: A resolution of the equity premium puzzle. Journal of Political Economy, 98, 519-543. http://dx.doi.org/10.1086/261693

Cowles \& Associates. (1939). Common stock indexes. Cowles commission monograph 3 (2nd ed.). Loomington: Principia Press.

Dimson, E., Marsh, P., \& Staunton, M. (2002). Triumph of the optimists: 101 years of global investment returns. Princeton: Princeton University Press.

Dimson, E., Marsh, P., \& Staunton, M. (2004). Irrational optimism. Financial Analyst Journal, 60, 15-25.http://dx.doi.org/10.2469/faj.v60.n1.2589

Dimson, E., Marsh, P., \& Staunton, M. (2008). The worldwide equity premium: A smaller puzzle. In R. Mehra (Ed.), The Handbook of The Equity Risk Premium (pp. 467-514). North Holland: Elsevier.

Dokko, Y., Park, J., \& Cho, J. (2001). The equity premium puzzle: The case in Korea. Asian Review of Financial Studies, 14, 1-22.

Ferson, W., \& Harvey, C. (1992). Seasonality \&consumption-based asset pricing. Journal of Finance, 47, 511-522. http://dx.doi.org/10.1111/j.1540-6261.1992.tb04400.x

Ferson, W., \& Constantinides, G. (1991). Habit persistence and durability in aggregate consumption: empirical test. Journal of Financial Economics, 29, 199-240. http://dx.doi.org/10.1016/0304-405X(91)90002-2

Friend, I., \& Blume, M. (1975). The demand for risky assets. American Economic Review, 65, 900-922.

Gabaix, X. (2008). Variable Rare Disasters: A tractable theory of ten puzzles in macro-finance. American Economic Review: Papers \&proceedings, 98, 64-67. http://dx.doi.org/10.1257/aer.98.2.64

Heaton, J. (1993). The interaction between time-nonseparable preferences and time aggregation. Econometrica, 61, 353-385. http://dx.doi.org/10.2307/2951555

Huggett, M. (1993). The risk-free rate in heterogeneous-agent incomplete-insurance economies. Journal of Economic Dynamics and Control, 17, 953-969. http://dx.doi.org/10.1016/0165-1889(93)90024-M

Hung, M. (1994). The Interaction between Nonexpected Utility and Asymmetric Market Fundamentals. Journal of Finance, 49, 325-343. http://dx.doi.org/10.1111/j.1540-6261.1994.tb04433.x

Ibbotson Associates. (2001). Stocks, bonds, bills \&inflation, 2000 yearbook. Chicago: Ibbotson Associates.

Jagannathan, R., McGrattan, E., \& Scherbina, A. (2000). The declining U.S. equity premium. Federal Reserve Bank of Minneapolis Quarterly Review, 24, 3-19.

Jorion, P., \& Goetzmann, W. (1999). Global stock markets in twentieth century, Journal of Finance, 54, 953-980. http://dx.doi.org/10.1111/0022-1082.00133

Kandel, S., \& Stambaugh, R. (1991). Asset returns and intertemporal preferences. Journal of Monetary Economics, 27, 53-73. http://dx.doi.org/10.1016/0304-3932(91)90004-8

Kang, M. (2008). An empirical study on the equity premium and the risk aversion coefficient in the Korean stock market. Korean Applied Economy, 10, 33-49.

Kim, I., \& Hong, C. (2008). Equity premium puzzle in Korean stock market. AsianReview of Financial Studies, 21, $1-32$.

Kocherlakota, N. (1996). The equity premium puzzle: It's still a puzzle. Journal of Economic Literature, 34, 42-71.

Kydland, F., \& E. Prescott, E. (1982). Time to build and aggregate fluctuations. Econometrica, 50, 1345-1371. http://dx.doi.org/10.2307/1913386

McGrattan, E., \& Prescott, E. (2000). Is the Stock Market Overvalued?. Federal Reserve Bank of Minneapolis Quarterly Review, 24, 20-40.

Mehra, R., \& Prescott, E. (1985). The equity premium: A puzzle. Journal of monetary Economics, 15, 146-161. http://dx.doi.org/10.1016/0304-3932(85)90061-3 
Mehra, R., \& Prescott, E. (2003). The equity premium in retrospect. In G. M. Constantinides, M. Harris, \& R. Stulz, (Eds.), Handbook of the Economics of Finance (Chapter 14). Amsterdam: Elsevier.

Parker, J., \& Julliard, C. (2005). Consumption risk \&the cross section of expected return. Journal of Political Economy, 113, 185-222. http://dx.doi.org/10.1086/426042

Rietz, T. (1988). The equity risk premium: A solution?. Journal of Monetary Economics, 21, 117-132. http://dx.doi.org/10.1016/0304-3932(88)90172-9

Schwert, G.W. (1990). Indexes of U.S. stock prices from 1802 to 1987. Journal of Business, 63, 399-426. http://dx.doi.org/10.1086/296513

Shiller, R. (1990). Market atility. Cambridge: MIT press.

Siegel, J. (1992a). The real rate of interest from 1800-1990: A study of the U.S. and the U.K. Journal of Monetary Economics, 29, 227-252. http://dx.doi.org/10.1016/0304-3932(92)90014-S

Siegel, J. (1992b). The equity premium: stockand bond returns since 1802. Financial Analysts Journal, 48, 28-38. http://dx.doi.org/10.2469/faj.v48.n1.28

Siegel, J. (1998). Stocks for the long run (2nd ed.). New York, NY: Irwin.

Siegel, J. (1999). The shrinking equity premium. Journal of Portfolio Management, 26, 10-17. http://dx.doi.org/10.3905/jpm.1999.319776

Siegel, J. (2005). Perspectives on the equity risk premium. Financial Analyst Journal, 61, 61-73. http://dx.doi.org/10.2469/faj.v61.n6.2772

Siegel, J., \& Thaler, R. (1997). Anomalies: The equity premium puzzle. Journal of Economic Perspectives, 11, 191-200. http://dx.doi.org/10.1257/jep.11.1.191

Smithers, A., \& Wright, S. (2000). Valuing wall street. New York, NY: McGraw-Hill.

Weil, P. (1989). The equity premium puzzle and the riskfree rate puzzle. Journal of Monetary Economics, 24, 401-421. http://dx.doi.org/10.1016/0304-3932(89)90028-7

Weil, P. (1992). Equilibrium asset prices with undiversifiable labor income risk. Journal of Economic Dynamics and Control, 16, 401-421. http://dx.doi.org/10.1016/0165-1889(92)90057-L

Welch, I. (2000). Views of financial economists on the equity premium and on professional controversies. Journal of Business, 73, 501-537. http://dx.doi.org/10.1086/209653

\section{Notes}

Note 1. Hung (1994) and Bansal and Yaron (2004) provide partial solutions to the two puzzles using Epstein and Zin's utility. However, their success is very dependent upon underlying assumptions about the return and consumption processes that eventually rely on long-run growth in consumption.

Note 2. Equation (8.2.6), p. 306, in Campbell et al. (1997).

Note 3. From 1962 to 1982, the nominal interests on time deposits were calculated in basis of time span-weighted average, above 15 per cent in most years.

Note 4. Supplementary Table 1 is available upon request.

Note 5. The tables pertinent to these graphs are available upon request.

Note 6. Equation (8.4.11), p. 328, in Campbell et al. (1997). See derivation of the implied risk-free rate in Appendix 1.

Note 7. Tables are available on request.

Note 8. Supplementary Table 3 is available upon request. Panels D in supplementary Table 3, for instance, presents the implied risk-free rate generated by the external habit model in the case of $\kappa=0.9$ and $\kappa=0.7$ in conjunction with a time preference value of between 0.98 and 1.01 and a risk aversion of one to ten, respectively. These panels show that the generated risk-free rates increase as relative risk aversion grows from one to ten across all time preferences. However, each average of the implied risk-free rate generated by interest rates on time deposits exceeds the mean of observed returns row by row, implying that the former does not meet the mean restriction of the latter for either the degrees of time or non-separability. In other words, this is an unanticipated result since we expect the generated interest rate via the external habit ratio model to meet the first moment condition in the way that other proxies do. This failure might arise because of the attributes of the financial instrument, namely interest rates on time deposits are distinct from any other proxy or the recent declining trend, as shown in Panel A in Figure 1. Observed returns are too low to be explained by a pseudo-interest rate process (Weil, 1989).Supplementary Tables are available 
on request.

Appendix 1. Risk-free Rate derived from External Habit Formation

If the representative agent's consumption equals aggregate consumption, the Euler equation is derived as follows:

$$
\frac{\partial U_{t}}{\partial C_{t}}=C_{t-1}^{\kappa(\rho-1)} C_{t}^{-\rho}-\beta \kappa C_{t}^{\kappa(\rho-1)} C_{t+1}^{-\rho}
$$

Since $\kappa(1-\rho) \geq 0$, we restrict $\kappa$ to be between zero and one in this paper so that $\rho$ must be greater than one. Equations (A.1) and (3) come from (8.4.8) and (8.4.9) in Campbell et al. (1997). Combining equation (A.1) with (3) yields.

$$
1=\beta E_{t}\left[\left(1+R_{t, t+1}\right)\left(\frac{C_{t}}{C_{t-1}}\right)^{\kappa(\rho-1)}\left(\frac{C_{t+1}}{C_{t}}\right)^{-\rho}\right]
$$

Employing the moment-generating function technique on the right-hand side of equation (A.2) gives us

$$
\begin{aligned}
& \beta E\left[e^{t_{1} r_{i, t+1}-t_{2} \rho \square c_{t+1}+\kappa(1-\rho) \square c_{t}}\right] \\
& =\beta e^{\kappa(1-\rho) \square c_{t}} e^{t_{1} r_{i, t+1}-t_{2} \rho \square c_{t+1}} \times \\
& \int_{-\infty}^{+\infty} \int_{-\infty}^{+\infty} \frac{1}{2 \pi \sigma_{r} \sigma_{\square c} \sqrt{1-\varphi_{r, \square c}}} e^{-\frac{1}{2\left(1-\varphi_{r, \square c}^{2}\right)}\left[\left(\frac{r_{i, t+1}-\mu_{r}}{\sigma_{r}}\right)^{2}-2 \varphi_{r, \square c}\left(\frac{r_{i, t+1}-\mu_{r}}{\sigma_{r}}\right)\left(\frac{\square c_{t+1}-\mu_{\square c}}{\sigma_{\square c}}\right)+\left(\frac{\square c_{t+1}-\mu_{\square c}}{\sigma_{\square c}}\right)^{2}\right]} d r_{i, t+1} d \square c_{t+1}
\end{aligned}
$$

$r_{i, t+1}=\ln \left(1+R_{i, t+1}\right)$ and $\square c_{t+1}=\ln \left(C_{t+1} / C_{t}\right)$ denote for each.

$\mu_{r}:$ mean of $r_{i, t+1}$

$\square c_{t+1}$ : mean of consumption growth

$\sigma_{r}:$ standard deviation of $r_{i, t+1}$

$\sigma_{\square c}:$ standard deviation of $\square c_{i, t+1}$

$\varphi_{r, \square c}:$ correlation of $r_{i, t+1}$ and $\square c_{i, t+1}$

Since the joint moment-generating function, $E\left[e^{t_{1} X+t_{2} Y}\right]$, for any two normal random variables $\mathrm{X}$ and $\mathrm{Y}$ is known as $e^{t_{1} \mu_{X}+t_{2} \mu_{Y}+\frac{1}{2}\left(t_{1}^{2} \sigma_{X}^{2}+\varphi_{X, Y} t_{1} t_{2} \sigma_{X} \sigma_{Y}+t_{2}^{2} \sigma_{Y}^{2}\right)}$, we obtain the joint moment-generating function of the random variables $r_{i, t+1}$ and $\square c_{t+1}$ as follows:

$=\beta e^{\kappa(1-\rho)} e^{\left[t_{1} \mu_{r}+t_{2} \mu_{\square c}+\frac{1}{2}\left(t_{1}^{2} \mu_{r}^{2}+t_{2}^{2} \mu_{t_{c}}^{2}-2 \rho t_{1} t_{2} \operatorname{cov}\left(r_{i, t+1}, \square c_{t+1}\right)\right)\right]}$

Taking the logarithm on both sides produces

$$
r_{i, t+1}=-\ln \beta
$$

Here, we assume homoscedasticity and joint lognormality of asset returns and consumption growth. 